\title{
Eliminating grammatical function assignment from hierarchical models of speech production: Evidence from the conceptual accessibility of referents
}

\author{
ROGER HAWKINS, MONA ALTHOBAITI, and YI MA \\ University of Essex
}

Received: April 21, $2011 \quad$ Accepted for publication: February 12, 2012

\begin{abstract}
ADDRESS FOR CORRESPONDENCE
Roger Hawkins, Department of Language and Linguistics, University of Essex, Wivenhoe Park, Colchester CO4 3SQ, UK. E-mail: roghawk@essex.ac.uk
\end{abstract}

\begin{abstract}
The assignment of grammatical functions has been a key feature of hierarchical (serial) models of speech production since their inception in the 1970s. This article argues that grammatical function assignment is neither sufficient nor necessary in such models. It reports a study of the effects of the conceptual accessibility of referents on the selection of English dative syntactic frames in production and shows that the effects relate to linear precedence rather than grammatical function assignment. A secondary topic addressed in the same study is whether second language speakers of English have difficulty integrating syntactic knowledge where it interfaces with conceptual accessibility in speech production. Findings suggest that advanced proficiency speakers do not and are qualitatively similar to native speakers. The implications of this for the interface hypothesis about second language acquisition are discussed.
\end{abstract}

It has long been known that the relative conceptual accessibility of the referents in a message, usually operationalized as the animacy or concreteness/imageability of those referents, affects the choice of syntactic structure that mature native speakers make in production (Bock \& Warren, 1985; Branigan \& Feleki, 1999; Branigan, Pickering, \& Tanaka, 2008; McDonald, Bock, \& Kelly, 1993). For example, in simple transitive clauses where one argument is animate and the other inanimate, speakers show a strong tendency to choose a syntactic structure that places the animate argument early in the clause. Speakers are statistically more likely to produce passive sentences of the form The sailor was carried by the boat, where the (derived) subject is conceptually more accessible, than they are to produce 
Hawkins et al.: Eliminating grammatical function assignment

passive sentences like The fridge was bought by the farmer, where the (derived) subject is conceptually less accessible.

One interpretation of these findings is that they are consistent with a two-stage model of syntactic planning for speech production (Bock \& Levelt, 1994; Ferreira \& Engelhardt, 2006; Garrett, 1975; among others). At the first stage a store of lemmas (lexical items with semantic and syntactic, but not phonological, features) is accessed that are associated with the content items of the message (the referents of nouns, verbs, and adjectives). In the Garrett-Bock-Levelt model grammatical functions (subject, direct object [DO]) are assigned to noun lemmas at this stage, which is known as the functional level of production planning. A lemma that is conceptually more accessible than another is retrieved first and assigned the subject function. Together with the verb lemma, this subject determines which syntactic frame is selected at the second level of syntactic planning: the positional level. For example, the selection of the lemmas for sailor and carry, where the message has determined that sailor is the theme argument of the verb and the functional level has assigned the subject function to sailor, will, in turn, determine the selection of a passive syntactic frame at the positional level: The sailor was carried by the boat. The selection of lemmas for farmer and buy, where farmer is the agent of buy, determines the selection of the subject function at the functional level and of an active syntactic frame at the positional level: The farmer bought a fridge.

There are two key characteristics of this model. First, the thematic (i.e., semantic) roles of noun lemmas, as well as grammatical functions, are necessarily assigned by the verb at the functional level. It is not enough to assign the subject role to sailor in the example given above. The subject role alone cannot distinguish The sailor carried the boat from The sailor was carried by the boat; sailor is the subject in both cases. The thematic role that sailor plays in the event described by the verb also needs to be assigned: theme or agent. Second, the conceptual accessibility effect implies that speech production proceeds incrementally (Bock \& Levelt, 1994, p. 949; Kempen \& Hoenkamp, 1987; Levelt, 1989). Branigan et al. (2008, p. 174) describe incrementality as follows: "the processor deals with fragments of information as and when they become available.... Speakers can begin to generate and articulate an utterance as soon as minimal input is available, rather than having to wait until all elements of the utterance have been retrieved." In other words, conceptual accessibility primes the activation of particular lemmas over others at the functional level of planning, but it is incrementality of processing that drives the early selection of a syntactic frame at the positional level before all the lemmas that will eventually be part of the utterance are fully retrieved.

An illustration of a fragment of this kind of model of speech production is given in Figure 1, where the intended outcome is The sailor was carried by the boat (loosely based on figure 1 in Bock \& Levelt, 1994, p. 946).

In the early studies of Bock and Warren (1985) and McDonald et al. (1993), the assignment of grammatical functions was central to the proposal of two stages of syntactic planning. It appeared to explain not only the effects of conceptual accessibility on syntactic frame selection where one lemma is conceptually more accessible than another but also why conceptual accessibility has no effect on conjoined noun phrases (NPs) in examples like The lost hiker fought time and winter or The lost hiker fought winter and time (where winter is more imageable, 
Hawkins et al.: Eliminating grammatical function assignment
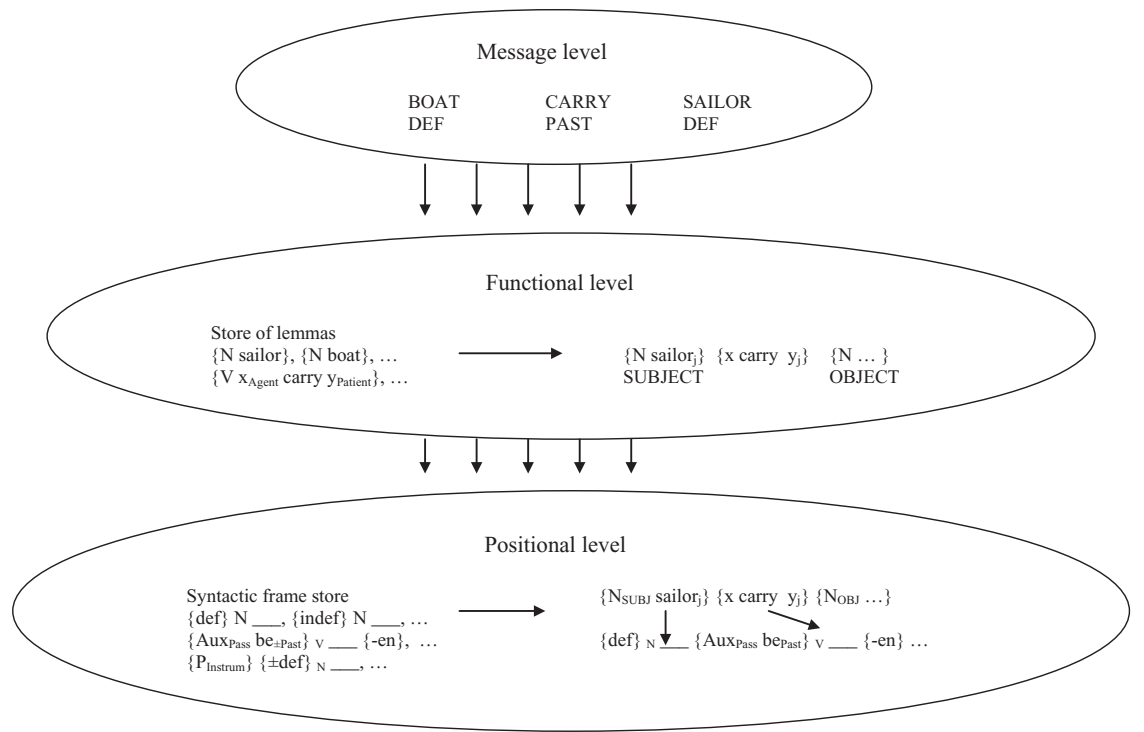

Figure 1. An illustration of a fragment of a sentence production model with two stages of syntactic planning.

and hence conceptually more accessible, than time; Bock \& Warren, 1985). In such cases it is assumed that a single grammatical function is assigned to both conjuncts. However, these early studies were based on results from native speakers of English, where the order in which grammatical functions appear typically coincides with the linear order of arguments in the sentence. It was assumed in a number of subsequent studies that, for this reason, English is not a good candidate for teasing apart the effects of conceptual accessibility on grammatical function assignment versus linear ordering (but see below, where this assumption is questioned).

More recent studies by Branigan and Feleki (1999) and Tanaka, Branigan, and Pickering (2005; reported in Branigan et al., 2008) suggest that conceptual accessibility may influence the selection of grammatical functions and earlier positioning in the clause independently. The Branigan and Feleki study used an oral sentence recall procedure with native speakers of Greek. In Greek, an overt case-marking language, although subject-verb-object (SVO) is the canonical word order for active transitive constructions, object-verb-subject (OVS) is also a possibility, since subjects are overtly marked for nominative case and objects for accusative case. Branigan and Feleki predicted that if conceptual accessibility (operationalized as animacy) led to early positioning in the sentence of a NP regardless of its grammatical function, their participants would recall (the Greek equivalent of) sentences like (1b) and (2a) as (1a) and (2b), respectively. However, if conceptual accessibility was relevant to grammatical function assignment and not word order, recall of (2a) as (2b) would be no more likely than recall of (1a) as (1b). 
Hawkins et al.: Eliminating grammatical function assignment

(1) a. In democratic regimes, the citizen $n_{\text {Nom }}$ respects the law Acc. $_{\text {(SVO) }}$

b. In democratic regimes, the law $_{\mathrm{Acc}}$ respects the citizen $\mathrm{Nom}_{\mathrm{Nom}}$ (OVS)

(2) a. In democratic regimes, the law $\mathrm{w}_{\mathrm{Nom}}$ respects the citizen $\mathrm{Acc}_{\mathrm{Acc}} \quad$ (SVO)

b. In democratic regimes, the citizen ${ }_{\mathrm{Acc}}$ respects the law $\mathrm{Nom}_{\mathrm{Nom}}$ (OVS)

Results showed that participants were statistically more likely to produce utterances where the animate NP came in the first position, regardless of whether it was the subject or the object, suggesting that conceptual accessibility affects the earlier positioning of NPs rather than assignment of grammatical functions.

However, in a study of Japanese native speakers (Japanese is also an overt case-marking language), Tanaka et al. (2005) found that both positioning and grammatical function were affected by conceptual accessibility. Using a similar design to Branigan and Feleki, Tanaka et al. presented participants with stimulus active and passive sentences in canonical Japanese SOV order and in scrambled OSV order. The OSV sentences were equivalent to the examples in (3) and (4).

(3) a. traveler $_{\text {Acc }} \operatorname{taxi}_{\text {Nom }}$ pick up Active $_{\text {A }}$

The taxi picked up the traveler.

b. taxi $_{\text {Obl }}$ traveler $_{\text {Nom }}$ pick up Passive $_{\text {Pas }}$

The traveler was picked up by the taxi.

(4) a. taxi $_{\text {Acc }}$ traveler ${ }_{\text {Nom }}$ pick up Active $_{\text {. }}$

The traveler picked up the taxi.

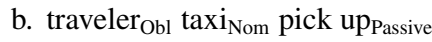

The taxi was picked up by the traveler.

Tanaka et al. found that participants were statistically more likely to recall sentences like (3a) as (3b) than sentences like (4a) as (4b). This is consistent with the conceptually more accessible NP having a greater effect on the assignment of the subject function than earlier positioning in the OSV construction. In a related experiment that only provided participants with stimulus active sentences in SOV and OSV word order (and did not include passive stimulus sentences), it was found that participants were more likely to recall OSV stimuli as SOV if the subject was animate, suggesting an effect of conceptual accessibility on early positioning in the sentence, regardless of grammatical function. Branigan et al. (2008, p. 184) consider these results to be evidence against a two-stage model of syntactic planning for production and in favor of a single level of syntactic planning at which arguments are assigned a grammatical function and a word order position simultaneously. This claim will be reexamined below.

\section{AIMS OF THE PRESENT STUDY}

The aims of the present study are the following:

1. to show that although in English the effects of the conceptual accessibility of referents on grammatical function assignment and linear ordering often coincide, the two can be distinguished in dative alternation constructions; 
2. to argue that in a model of speech production where verbs assign thematic roles and processing is incremental, grammatical functions are redundant and should be eliminated on grounds of theoretical parsimony, and consequently that conceptual accessibility only affects linear ordering at the positional level of production planning;

3. to test this claim in a study of the effects of conceptual accessibility on the production of dative constructions by native speakers of English, and additionally by second language (L2) speakers of English with first language (L1) Arabic and L1 Chinese; the interest of the latter relates to a current debate about whether L2 speakers do or do not have difficulty integrating syntactic knowledge where it interfaces with other mental representations (Sorace, 2005; Sorace \& Filiaci, 2006; White, 2011), in this case, the interface between syntactic representations and the conceptual accessibility of referents during speech production processing (see below for discussion); and

4. to reconsider the evidence adduced by Bock and Warren (1985), McDonald et al. (1993), and Branigan et al. (2008) that appears to support the necessity for grammatical function assignment in speech production.

\section{DISTINGUISHING CONCEPTUAL ACCESSIBILITY EFFECTS ON LINEAR ORDERING FROM GRAMMATICAL FUNCTION ASSIGNMENT IN ENGLISH}

In simple active-passive pairs like those illustrated in (5), preferred in production to the pair in (6) because of the greater conceptual accessibility of sailor over boat, it is impossible to tell whether this is because sailor occupies an early position in the clause or because it has been assigned the subject function, since the two coincide.

(5) a. The sailor carried the boat.

b. The sailor was carried by the boat.

(6) a. The boat was carried by the sailor.

b. The boat carried the sailor.

Cases like these might suggest that the locus of the effect of conceptual accessibility cannot be successfully determined in English.

However, dative verbs that allow the prepositional object-double object alternation can actually distinguish linear order from grammatical function assignment in English. Compare the sentences in (7)-(9). Those in (7) are tokens of prepositional object datives. Most syntactic theories assume that the determiner phrase (DP) immediately following the verb is a DO, whereas the prepositional phrase (PP) is an indirect object (IO). The difference between them is that in (7a) the DO is animate and the IO inanimate, while in (7b) the DO is inanimate and the IO animate. In the double object constructions in (8)-(9), however, two different assignments of grammatical functions are in principle possible. In (8) both DPs are assigned DO status, but in (9) the DP immediately following the verb retains its IO status. Again, the (a) examples differ from the (b) examples in whether the first DP is animate and the second one inanimate, or the reverse. In all the 
Hawkins et al.: Eliminating grammatical function assignment

examples, patient and customer are assumed to be more conceptually accessible than hospital and book.

(7) a. The doctor sent the patient to the hospital.

$$
\text { DO IO }
$$

b. The library sent the book to the customer.

DO IO

(8) a. The doctor sent the hospital the patient.

DO DO

b. The library sent the customer the book.

DO DO

(9) a. The doctor sent the hospital the patient.

IO DO

b. The library sent the customer the book.

IO DO

Assuming a standard grammatical function hierarchy where the DO is more prominent than the IO (Keenan \& Comrie, 1977), if the DP complements in the double object construction are both DOs, as in (8), in production models that assume that conceptual accessibility determines grammatical function assignment, speakers should be more likely to produce sentences like (8b), where the conceptually more accessible customer is a DO, than (7b), where it is an IO. There should be no difference, however, in the likelihood of speakers producing (7a) or (8a), because the conceptually more accessible patient is a DO in both cases. Nor should there be any greater tendency to produce ( $8 b)$ than $(8 a)$, because in both cases the conceptually more accessible noun has been assigned the DO function. The model that makes these predictions will be referred to as grammatical function model 1 (GF1), where the first of the verb's postverbal arguments is assigned the DO function.

By contrast, if the speech production model assumes that in the double object construction the first object retains its IO status, so that hospital and customer are IOs as in (9), there should be no greater tendency to produce (7a) than (9a), or (9b) than (7b), since in both cases the grammatical function of the conceptually more accessible argument remains the same: DO in the case of (7a)-(9a) and IO in the case of (7b)-(9b). The model that makes these predictions will be referred to as grammatical function model 2 (GF2).

If conceptual accessibility affects early linear positioning rather than grammatical function assignment, however, speakers should be not only more likely to produce (7a) than (9a) but also more likely to produce (9b) than (7b), because in (7a) and (9b) the conceptually more accessible argument appears earlier in the syntactic frame. This will be referred to as the linear precedence model. The predictions of the three models are summarized in Table 1.

These predictions are tested in the study of speech production to be reported subsequently. Before that, it will be argued that grammatical function assignment is redundant in a hierarchical model of speech production, and reasons will be given for including nonnative speakers of English in the study. 
Hawkins et al.: Eliminating grammatical function assignment

Table 1. Predictions of three models for the effects of conceptual accessibility on the production of datives

\begin{tabular}{|c|c|c|c|}
\hline \multirow[b]{2}{*}{ Sentence Types } & \multicolumn{3}{|c|}{ Construction (a) More Likely Than (b) } \\
\hline & GF 1 & GF 2 & Linear Precedence \\
\hline $\begin{array}{l}\text { (a) Send the customer the book } \\
\text { (b) Send the book to the customer }\end{array}$ & Yes & No & Yes \\
\hline $\begin{array}{l}\text { (a) Send the patient to the hospital } \\
\text { (b) Send the hospital the patient }\end{array}$ & No & No & Yes \\
\hline
\end{tabular}

Note: GF, grammatical function.

\section{THE REDUNDANCY OF GRAMMATICAL FUNCTION ASSIGNMENT IN HIERARCHICAL MODELS OF SPEECH PRODUCTION}

Many of the proposals for hierarchical (i.e., nonconnectionist) models of speech production have assumed that a core operation at the functional level of planning is the assignment of a grammatical function (subject, DO, IO, etc.) to each noun lemma accessed (Bock \& Levelt, 1994; Bock \& Warren, 1985; Branigan et al., 2008; Garrett, 1975; Kempen \& Hoenkamp, 1987; Levelt, 1989; among others). The assumption that subject, object, and so on are linguistically significant constructs is consistent with some models of grammar (e.g., lexical functional grammar; Bresnan, 2001), but not all. In principles and parameters/minimalist theories, functional roles like subject, object, and so on have no theoretical status. They are post hoc ways of labeling particular structural configurations that have been derived by syntactic computations but play no role in the interpretation or derivation of clauses.

A similar view can be taken of the role of grammatical function assignment in a model of speech production. As already observed above and illustrated in Figure 1, any hierarchical model of production planning needs to provide a mechanism by which the verb assigns thematic roles to the noun lemmas that constitute its arguments. This necessity shows up clearly in the case of sentences with potentially reversible meanings like those illustrated in (10) and (11).

(10) a. The student greeted the professor.

b. The student was greeted by the professor.

(11) a. The speculator sold the bank to the company.

b. The speculator sold the bank the company.

Student is the subject in both (10a) and (10b), and yet the meanings of the two sentences are different. This is because student is assigned greet's agent role in (10a) but patient role in (10b). Under the most plausible interpretation of grammatical function assignment by dative verbs, bank is a DO in both (11a) and (11b), because it can be passivized in both cases, and only DOs undergo passivization in English: The bank was sold to the company/The bank was sold 
Hawkins et al.: Eliminating grammatical function assignment

the company versus *The designer was introduced the engineer where designer can only be an IO. Yet the meaning of (11a) differs from that of (11b). Again this is due to a difference in thematic role assignment by the verb. In (11a) bank is the theme that passes from the speculator to the company. In (11b) bank is the goal of the transaction, taking possession of the company. Grammatical functions are thus not sufficient to determine the selection of the appropriate syntactic frame at the positional level to convey the message content. Is grammatical function assignment necessary?

Apparently not. In a model of speech production that assumes both that a verb assigns thematic roles to its arguments at the functional level and that the transmission of information from the functional level to the positional is incremental, this alone is sufficient to determine the selection of the appropriate syntactic frames. Grammatical function assignment is not necessary, and on grounds of theoretical parsimony should be eliminated. Consider the case of The student was greeted by the professor. One entry for greet in the store of lemmas will contain the information that it has two argument positions, an internal argument that is the recipient of the greeting (the "patient" in the event) and an external argument that is the instigator of the event (the "agent"). The entry might look something like the following ${ }^{1}$ :

\section{$\left\{\mathrm{V},\left[x_{\text {agent }}\left[\right.\right.\right.$ greet $\left.\left.\left.\left[y_{\text {patient }}\right]\right]\right]\right\}$}

The message level provides two key pieces of information for the production of The student was greeted by the professor. First, that the concept professor is the agent in the event and the concept student the patient; second, that student is conceptually more accessible than professor (for whatever reason: because it has been primed by an identical or related noun in some preceding stimulus, because it has already been mentioned in the discourse and is therefore the topic [PratSala \& Branigan, 1999], or because student's thematic role of patient has been primed by a focused constituent with a patient role in the preceding discourse [Chang, Bock, \& Goldberg, 2003; Vernice, Pickering, \& Hartsuiker, 2011]). The greater conceptual accessibility of student has the consequence that, when \{greet\} is activated in the store of lemmas, the noun lemma $\{$ student $\}$ is accessed before $\{$ professor $\}$. \{Student $\}$ is then coindexed with the patient role of the verb.

$$
\left\{\mathrm{V},\left[x_{\text {agent }}\left[\text { greet }\left[y_{\text {patient }}\right]\right]\right]\right\}\{\mathrm{N} \ldots\}_{\text {xagent }},\{\mathrm{N} \text { student }\}_{\text {ypatient }}
$$

Incrementality of processing ensures that the representation in (13) passes on to the positional level before \{professor \} has been retrieved. Assuming that a key feature of positional level processing is left to right assignment of linear order to hierarchically structured (but unordered) constituents, a syntactic frame cannot be selected where the first noun position has no noun lemma to fill it. This would be the case if (13) activated an active transitive syntactic frame. Therefore, (13) activates a syntactic frame where the $y$ argument of the verb \{greet\} can fill the first empty N position: a passive frame. ${ }^{2}$

No access to thematic role information at the positional level is required. The information that a verb (and other predicates) provides to the positional level is 
Hawkins et al.: Eliminating grammatical function assignment

the number of its arguments, their hierarchical relation to the verb (i.e., external argument, first internal argument, or second internal argument), and the set of syntactic frames in which the verb can potentially appear. For example, \{greet\} provides the information that it is a two-argument verb- $\{[x$ [greet $[y]]]\}-$ and that it can appear in active and passive syntactic frames. As already described, incrementality of processing and the indexing of noun lemmas with either the verb's $x$ or $y$ argument will automatically determine which syntactic frame is selected at the positional level.

It is necessary for verbs (and other predicate) lemmas to contain information about the possible frames they can appear in at the positional level to deal with cases where verbs of the same semantic class differ in the set of syntactic frames in which they can appear. For example, whereas send $-\left\{\mathrm{V},\left[x_{\text {agent }}\left[\right.\right.\right.$ send $\left[y_{\text {theme }}\right]$ $\left.\left.\left.\left[z_{\text {recipient }}\right]\right]\right]\right\}$ - can appear both in prepositional object and double object frames (send the book to the customer, send the customer the book), the semantically very similar verb despatch with the same argument structure can only appear in the prepositional object frame (despatch the book to the customer, *despatch the customer the book).

The inaccessibility of thematic role information to processing at the positional level is consistent with the findings from a number of priming studies, which suggest that previously heard or produced structures activate syntactic frames for production that have the same syntactic-category-level representation as the primes, even where the thematic and conceptual properties of the prime and the target are different (Bock, 1986; Bock \& Loebell, 1990; Pickering \& Branigan, 1998; Pickering, Branigan, \& McLean, 2002). For example, Bock and Loebell (1990) found that transitive verbs with locative adjuncts like The wealthy widow drove her Mercedes to the church primed prepositional dative constructions like $A$ rock star sold some cocaine to an undercover agent. The thematic role information of the prime here is not relevant to that of the target. At the same time, mere phonological similarity is not sufficient to prime syntactic frames at the positional level. Primes like Susan brought a book to study did not prime targets like The girl gave a book to the man. The difference in syntactic category status of to in the prime (it is a nonfinite exponent of the tense category) and to in the target (an exponent of the preposition category) clearly is relevant for the priming of syntactic frames at the positional level. ${ }^{3}$

If grammatical functions are no longer assigned in speech production planning, the effects of conceptual accessibility can only relate to linear ordering. Lemmas for conceptually more accessible entities are selected first at the functional level, along with the associated verb (or more generally the predicate). Incrementality of processing activates a syntactic frame where the selected noun lemma can appear in the first available slot. In the next section the rationale for investigating this claim in nonnative, as well as native, speakers of English is discussed. This is followed by the report of the study itself.

\section{TESTING THE INTERFACE HYPOTHESIS IN SPEECH PRODUCTION}

The reason for including nonnative as well as native speakers in the present study was to test the extent to which speech production planning and the effects of 
Hawkins et al.: Eliminating grammatical function assignment

conceptual accessibility are similar in both groups. A current debate in research into L2 acquisition centers on whether L2 speakers are able to successfully integrate grammatical knowledge with nongrammatical knowledge from other modules of mind during real-time communication. Some researchers argue that such integration poses persistent difficulties for L2 speakers. For example, Sorace (2005) has argued for the following hypothesis:

Interface hypothesis

a. Features that are internal to the computational system of syntax proper are acquired successfully by adult L2 learners ... endstate (near-native) grammars converge with native grammars.

b. Features that belong to the interface between syntax and other domains, such as the lexicon, discourse, or pragmatics, may never be completely acquired by L2 learners. (Sorace, 2005, example 26)

Although formulated on the basis of evidence from studies of comprehension by L2 speakers, the theory has potential implications for L2 speech production too.

An assumption made in the present study is that, just as in comprehension, normal speech production involves the integration of syntactic knowledge with nonlinguistic conceptual and discourse information. That is, speech production is a domain in which there is an interface between different levels of representation. The interface between syntactic and discourse knowledge is illustrated by examples like those in (14) and (15).

(14) Who ate the cake?

(15) What did Maria eat? a. Maria ate the cake.

b. The cake was eaten by Maria.

a. Maria ate the cake.

b. \#The cake was eaten by Maria.

Syntactically both Maria ate the cake and The cake was eaten by Maria are grammatical, but the felicity of selecting one or other of these constructions as an utterance is determined by the discourse in which they appear. The choice of the passive (15b) as a response to the question in (15) is infelicitous (indicated by \#) because Maria, who is a topic by virtue of the question asked about her, appears in a syntactic position that is interpreted as focus (new discourse information) in English. The choice of the passive as an answer to (14) is perfectly felicitous because Maria provides the new information requested in an appropriate syntactic position. By contrast, (14a) is only felicitous where there is contrastive stress on Maria, which has the effect of shifting focus from cake to Maria. This is a case in which there is an interface between syntactic knowledge and memory for discourse information that determines the felicity of the utterance.

The conceptual accessibility of referents and its effect on the selection of syntactic constructions illustrates the interface between conceptual and syntactic structure. There is nothing in the syntactic representations of The boat was carried by the sailor and The sailor was carried by the boat (both passives) to explain why the latter is more likely to be produced by native speakers than the former. The effect 
lies in the asymmetry of the conceptual accessibility of the referents. As already described, the information that one referent is conceptually more accessible than another determines the selection of a particular syntactic frame via the order of activation of lemmas. The effect at this interface could be otherwise, however. There could be an anticonceptual accessibility effect, where a lemma corresponding to a conceptually less accessible antecedent is selected first. This would lead speakers to be more likely to produce The boat was carried by the sailor than The sailor was carried by the boat. Or there might be no effect of conceptual accessibility at all, so that both constructions are equally likely to be uttered. Moreover, the kinds of syntactic construction that are activated by the conceptual accessibility of referents are likely to be language specific. The sentence recall study of Tanaka et al. (2005) found that speakers of Japanese produce active sentences in response to passive stimuli, where a conceptually more accessible referent is in the by phrase (e.g., A taxi was picked up by a traveler recalled as $A$ traveler picked up a taxi) at a rate of $6 \%$ (see the Discussion section below for more detail). This contrasts dramatically with the native English speakers in the present study, whose rate of recall of similar passive sentences as actives was $74 \%$. This suggests that actives and passives are organized differently for the purposes of speech production in Japanese and English.

If L2 speakers never completely acquire the features at the interface, a possible prediction for speech production is that where the conceptual accessibility of referents and the selection of syntactic frames interact, L2 speakers will diverge from native speakers. The L1s of the L2 speakers in the present study are Arabic and Mandarin Chinese. These languages were chosen because they both have dative prepositional object and dative double constructions, similar to English, as illustrated in (16) and (17). If difficulty in integrating information about the conceptual accessibility of referents with the selection of syntactic constructions applies generally to L2 speakers, the fact that both L1s have similar properties to the target L2 should be irrelevant; both groups should differ in speech production from native speakers.

Chinese

(16) a. Wo chang gei jia ren fa duanxin

I often to family send text message

"I often send a text message to my family."

b. Ta song le wo yi liang zixingche

He give Perf I one Classifier bicycle

"He gave me a bicycle."

Arabic

(17) a. 'a 'Tay-tu 1-kitaab-a li-1-bint-i

gave-I the-book to-the-girl

"I gave the book to the girl."

b. 'a 'Tay-tu 1-bint-a 1-kitaab-a

gave-I the-girl the-book

"I gave the girl the book."

(Arabic examples from Ryding, 2005)

The next section reports the study. In a subsequent section, apparently problematic cases for the linear-ordering claim (lack of effects of conceptual accessibility 
Hawkins et al.: Eliminating grammatical function assignment

on the order of nouns in conjoined phrases, the findings of Tanaka et al., 2005, that in Japanese conceptual accessibility affects both linear ordering and grammatical function assignment) will be reconsidered.

\section{THE STUDY}

Table 1 outlined the predictions of two models of grammatical function assignment and a linear precedence model for the effects of the conceptual accessibility of noun lemmas on the selection of syntactic frames with English alternating dative verbs (give, send, offer, etc.). To test these predictions for speech production, a delayed oral sentence recall task was designed. A recall task was chosen because, as McDonald et al. (1993, pp. 196-197) observe, "The reconstruction that underlies the recall of linguistic materials rests heavily upon normal production mechanisms" and "permits better control of the target sentences across a wider range of lexical contents and sentence types than is possible with less constrained production tasks" (cf. Potter \& Lombardi, 1990, who propose that a "sentence is regenerated in immediate recall from a representation of its meaning," p. 633).

There is a potential danger with recall tasks, of course, of unwanted priming effects from earlier trials persisting into later trails. This was controlled for in the present study (a) by introducing a delay between the presentation of blocks of stimulus sentences and requiring participants to recall those stimuli and (b) by including a baseline set of active and passive sentence stimuli where the conceptual accessibility of the verb's arguments was systematically manipulated to induce changes in the syntactic structure of the target utterance. The effects of the conceptual accessibility of the verb's arguments should outweigh any priming effects from the stimulus if normal production mechanisms are in play.

\section{Method}

Participants. Ten native speakers of English ( 5 female, 5 male), 15 native speakers of Mandarin Chinese (11 females, 4 males), and 17 native speakers of (Saudi) Arabic (all female) participated in the study. Eleven of the Chinese participants were third- or fourth-year undergraduate students studying English in China. This group were aged from 21 to 23 and had had an average of 11.5 years of classroom English input and no significant exposure to English outside of China. The remaining four were university teachers of English ranging in age from 35 to 38 with an average of more than 25 years of exposure to English in the classroom and in English-speaking communities. The Chinese participants were tested in China. The Saudi Arabic participants were all postgraduate students at a UK university, and ranged in age from 24 to 34 years. They had all been exposed to English in a classroom setting for more than 10 years and had spent between 7 and 60 months in an English-speaking community. The 10 members of the control group were speakers of British or American English, undergraduate or postgraduate students at a UK university, ranging in age from 20 to 54.

Materials. As already described, the main test instrument was a delayed sentence recall task. Sentences were presented to participants bimodally (simultaneous 
auditory and visual presentation) using Microsoft Powerpoint. The written versions of sentences appeared in black 24-point Arial font in the center of a white screen (one sentence per slide). Sentences were grouped into 16 blocks of 5 . Immediately following each block, participants answered between two and five multiple-choice questions from an English proficiency test (the Oxford Quick Placement Test, 2002). The function of this task was both to provide a general measure of participants' proficiency in English and to introduce a delay between the presentation of the stimulus sentences and the recall of those sentences by participants. The aim was to reduce the possibility of verbatim recall of the sentences and the potential priming effect of the syntactic structure of the stimuli on recall. An example of a test block is illustrated in Appendix A.

Baseline active/passive sentences and experimental dative double object/prepositional object sentences were constructed from two sets of nouns differentiated by animacy (strictly speaking "humanness").

(16) a. Animate

student, professor, child, teacher, patient, doctor, baker, actress, sailor, dancer, farmer, waiter, policeman, artist, cook, climber, fireman, electrician, walker, player, manager, assistant, customer, painter, wife, friend

b. Inanimate

fridge, bottle, bicycle, painting, cake, boat, ice, bell, wire, soup, book, holiday, car, hospital, team, company, organization ${ }^{4}$

The verbs used in the dative sentences involved transfer of possession (send, sell, lend) or future transfer of possession (offer, promise). Five types of sentence were represented in the blocks for recall. These are illustrated in Table 2.

Thus, there were 30 baseline items, 16 experimental items, and 34 fillers in the test. The purpose of including the introductory locative PPs with the transitive verbs, and the manner adverbs with the simple past intransitive fillers, was to roughly equalise the length of the stimulus sentences in the test. Each stimulus sentence was between 7 and 10 words long. The full set of test items is given in Appendix B.

When participants had heard/read a block of five stimulus sentences and completed the multiple-choice questions of the Oxford Quick Placement Test that followed them, they were shown prompts. For the baseline and experimental items, these consisted of three nouns drawn from the stimulus and presented in a random vertical order, for example,

boat

harbour

sailor

No verb was included in the prompts on the grounds that it might prime an active sentence in recall. The order in which the prompts were presented did not match the order in which the stimulus sentences were heard. ${ }^{5}$

All 60 items of the Oxford Quick Placement Test were included as part of the experimental design, allowing a measure of the general proficiency in English of 
Hawkins et al.: Eliminating grammatical function assignment

Table 2. The sentence types that were tested

Baseline Stimuli

(i) Active transitive sentences preceded by a locative PP

(a) where both arguments were animate, e.g., At the university, the student greeted the professor (5 items)

(b) where the subject was animate and the object inanimate, e.g., At the market, the farmer bought the fridge (5 items)

(c) Where the subject was inanimate and the object animate, e.g., In the harbour, the boat carried the sailor (5 items)

(ii) Passive transitive sentences preceded by a locative PP

(a) where both arguments were animate, e.g., At the university, the professor was greeted by the student ( 5 items)

(b) where the (derived) subject was animate and the noun in the by-phrase inanimate, e.g., In the harbour, the sailor was carried by the boat (5 items)

(c) Where the (derived) subject was inanimate and the noun in the by-phrase animate, e.g., At the market, the fridge was bought by the farmer (5 items)

Experimental Stimuli

(iii) Dative sentences with double objects

(a) where the first object was animate and the second object inanimate, e.g., The bookshop sent the customer the book (4 items)

(b) where the first object was inanimate and the second object animate, e.g., The writer lent the organisation her personal assistant (4 items)

(iv) Dative sentences with a direct object + prepositional object structure

(a) where the direct object was animate and the noun in the PP inanimate, e.g., The doctor sent the patient to the local hospital (4 items)

(b) where the direct object was inanimate and the noun in the PP animate, e.g., The bookshop sent the book to the customer (4 items)

Filler Stimuli

(v) Sentences of the form locative PP + intransitive clause in the past progressive/ locative PP + intransitive clause in the simple past + manner adverb, e.g., At the library, the professor was reading (17 items), At the library, the professor read quietly (17 items)

Note: PP, prepositional phrase.

the participants. The scores achieved by participants are matched to standardized descriptions of proficiency. For example, test takers scoring between 18 and 29 are described as "elementary," between 30 and 47 as "intermediate," between 48 and 54 as "advanced," and between 55 and 60 as "very advanced."

Procedure. Each participant was tested individually with one of the coauthors present. The test session began with a general explanation of what the test involved and the collection of general biographical/language experience data from the 
Table 3. Participant scores on the Oxford Quick Placement Test

\begin{tabular}{lccc}
\hline \hline & Elementary & Intermediate & Advanced/Very Advanced \\
\hline L1 Arabic & 2 & 9 & 6 \\
L1 Chinese & 0 & 13 & 2 \\
L1 English & 0 & 0 & 10 \\
\hline \hline
\end{tabular}

Note: L1, first language.

participants. An example of a complete test block was then worked through with the participant before the main test began.

Scoring. The categories used for scoring the sentences produced by the participants were correct (recall of the original sentence in the same order), inversion (change from an active stimulus to a passive response, from a passive stimulus to an active response, from a double object stimulus to a DO $+\mathrm{PP}$ response, or from a DO + PP stimulus to a double object response), and other (any response that was not the same as the original sentence and was not an inversion, such as no response, partial response, or completely different word order).

The key evidence for determining the effects of conceptual accessibility is provided by the number of inversions in production. As Bock and Warren (1985, p. 57) note, "Absolute recall level [i.e., number of stimuli correctly recalled] is only of interest with respect to the question of the memorability of sentences, and not with respect to the question of the syntactic form in which the sentence is expressed." However, because the number of other responses is potentially variable, numbers of inversions for each stimulus type in the test cannot be compared directly. Inversion ratios were therefore calculated from the number of inversions divided by the total number of correct and inversion responses. Each table of results presents both the raw correct, inversion, and other scores, and the inversion ratio scores, which are the basis for inferential statistical comparisons.

The relationship between the ratio scores of an individual participant and the other participants in the sample is ordinal in nature. For each sentence type tested, there is a scale of possible inversions from the stimuli, from 1 to 5 in the case of the baseline sentence types and from 1 to 4 in the case of the experimental sentence types. Wilcoxon signed ranks tests were therefore used for the inferential statistics, with 0.05 as the alpha level for significance.

\section{RESULTS}

\section{Proficiency in English}

Table 3 compares the general proficiency levels of the three groups. As expected, all the native speakers fell into the advanced/very advanced category. It can be seen that the L2 participants represent a range of general proficiency in English with the majority at the intermediate level, as defined by the Oxford Quick Placement 
Hawkins et al.: Eliminating grammatical function assignment

Table 4. Recall of transitive sentences where both subject and object/ object of a by-phrase are animate

L1

\begin{tabular}{|c|c|c|c|}
\hline \multirow[b]{2}{*}{ Stimulus } & \multirow{2}{*}{$\frac{\operatorname{Arabic}(N=17)}{k=85}$} & \multirow{2}{*}{$\frac{\text { Chinese }(N=15)}{k=75}$} & \multirow{2}{*}{$\frac{\text { English }(N=10)}{k=50}$} \\
\hline & & & \\
\hline Correct active & 60 & 56 & 43 \\
\hline Inversion & 2 & 0 & 2 \\
\hline Other & 23 & 19 & 5 \\
\hline \multirow[t]{2}{*}{ Inversion ratio } & 0.04 & 0 & 0.04 \\
\hline & $k=85$ & $k=75$ & $k=50$ \\
\hline Correct passive & 50 & 56 & 31 \\
\hline Inversion & 18 & 13 & 14 \\
\hline Other & 17 & 6 & 5 \\
\hline Inversion ratio & 0.25 & 0.19 & 0.32 \\
\hline
\end{tabular}

Note: L1, first language. Arabic: $z=-2.23, N-$ ties $=11, p=.026$, two-tailed significance; Chinese: $z=-2.69, N-$ ties $=9, p=.007$, two-tailed significance; English: $z=-2.59, N-$ ties $=9, p=.01$, two-tailed significance.

Test. The role that proficiency plays in determining patterns of sentence production is discussed below in connection with performance on recall of the dative stimuli.

\section{Baseline results: Actives and passives}

It is well known that when factors like animacy and definiteness are held constant, and discourse effects are neutralized (as in sentences produced "out of the blue"), native speakers of English show a preference for producing actives over passives (Ferreira, 1994; Ferreira \& Engelhardt, 2006; Goldman-Eisler \& Cohen, 1970). It is thus expected that the native speakers in the present study will show a similar preference, and it is predicted that if the L2 speakers are successful in integrating grammatical representations with speech production mechanisms, they will show a similar preference. Table 4 presents the oral recall results (raw scores and inversion ratios) of active and passive stimuli where both arguments of the verb are animate and definite. The results of nonparametric Wilcoxon signed ranks tests (for repeated measures) comparing each group's inversion ratios for active and passive sentences are presented below the table. All three groups show a baseline preference for active over passive syntactic frames in production where factors like animacy, definiteness, and discourse status are held constant.

If the conceptual accessibility of the referents of a verb's arguments has an impact on the order in which lemmas are activated, with a consequent effect on 
Table 5. Recall of passive stimuli with animate and inanimate subjects

\begin{tabular}{|c|c|c|c|}
\hline \multirow[b]{3}{*}{ Stimulus } & \multicolumn{3}{|c|}{ L1 } \\
\hline & Arabic $(N=17)$ & Chinese $(N=15)$ & English $(N=10)$ \\
\hline & $k=85$ & $k=75$ & $k=50$ \\
\hline \multicolumn{4}{|c|}{ Passive animate subject } \\
\hline Correct & 43 & 64 & 40 \\
\hline Inversion & 6 & 1 & 3 \\
\hline Other & 36 & 10 & 7 \\
\hline \multirow[t]{2}{*}{ Inversion ratio } & 0.11 & 0.01 & 0.07 \\
\hline & $k=85$ & $k=75$ & $k=50$ \\
\hline \multicolumn{4}{|c|}{ Passive inanimate subject } \\
\hline Correct & 35 & 39 & 10 \\
\hline Inversion & 41 & 24 & 37 \\
\hline Other & 9 & 12 & 3 \\
\hline Inversion ratio & 0.52 & 0.40 & 0.78 \\
\hline
\end{tabular}

Note: L1, first language. Arabic: $z=-3.3, N-$ ties $=14, p=.001$, two-tailed significance; Chinese: $z=-3.05, N-$ ties $=13, p=.002$, two-tailed significance; English: $z=-2.63, N-$ ties $=9, p=.009$, two-tailed significance.

syntactic frame selection (through incrementality of processing), as already shown in studies of native speakers of English by Bock and Warren (1985) and McDonald et al. (1993), it is predicted that the preference for actives shown by participants in Table 4 will be overridden where the conceptual accessibility of the arguments of transitive verbs is asymmetric. This should manifest itself in two ways. First, where the first (subject) argument of a passive stimulus sentence is inanimate and the argument in the by phrase is animate, there should be a higher inversion ratio in production than in the reverse case. That is, speakers should be more likely to recall The fridge was bought by the farmer as The farmer bought the fridge than The sailor was carried by the boat as The boat carried the sailor. Second, participants should be no more likely to recall a passive stimulus sentence as an active where the first (subject) argument is animate and the argument in the by phrase is inanimate (The sailor was carried by the boat) than to recall an active stimulus as a passive where the first argument is animate and the second argument is inanimate (The farmer bought the fridge). If the L2 participants in the present study are able to integrate syntactic representations and the conceptual accessibility of referents during speech production, it is predicted that they will show similar production patterns to native speakers. Results for these two comparisons are presented in Table 5 and Table 6.

The results show that where the first (subject) argument of stimulus passive sentences is inanimate and the argument in the by phrase is animate, all three groups of participants are significantly more likely to produce an active sentence in recall 
Hawkins et al.: Eliminating grammatical function assignment

Table 6. Recall of transitive sentences where the subject is animate and the object/object of a by-phrase inanimate

\begin{tabular}{|c|c|c|c|}
\hline \multirow[b]{3}{*}{ Stimulus } & \multicolumn{3}{|c|}{ L1 } \\
\hline & Arabic $(N=17)$ & Chinese $(N=15)$ & English $(N=10)$ \\
\hline & $k=85$ & $k=75$ & $k=50$ \\
\hline Correct active & 72 & 62 & 49 \\
\hline Inversion & 11 & 0 & 1 \\
\hline Other & 2 & 13 & 0 \\
\hline \multirow[t]{2}{*}{ Inversion ratio } & 0.13 & 0 & 0.02 \\
\hline & $k=85$ & $k=75$ & $k=50$ \\
\hline Correct passive & 43 & 64 & 40 \\
\hline Inversion & 6 & 1 & 3 \\
\hline Other & 36 & 10 & 7 \\
\hline Inversion ratio & 0.11 & 0.01 & 0.07 \\
\hline
\end{tabular}

Note: L1, first language. Arabic: $z=-0.46, N-$ ties $=10, p=.65$, twotailed not significant; Chinese: $z=-1.0, N$ - ties $=1, p=.32$, two-tailed not significant; English: $z=-0.82, N$-ties $=3, p=.41$, two-tailed not significant.

than where the first (subject) argument of the passive is animate. Furthermore, the rate of inversion following passive stimuli of the latter kind is no greater than inversion following active stimuli where the first (subject) argument is animate. For all three groups, when the conceptual accessibility of a transitive verb's arguments is asymmetric, the inherent preference for producing active syntactic frames over passive is overridden. This was predicted in the case of the native speakers on the basis of previous work by Bock and Warren (1985) and McDonald et al. (1993). It was not initially known whether conceptual accessibility would have the same effect on speech production in the L2 groups. ${ }^{6}$ The results suggest that, in the case of the production of actives and passives in English, the L2 speakers are successfully integrating syntactic and conceptual representations during speech production planning.

\section{Experimental results: Datives}

Although the results from the recall of active and passive stimulus sentences allow us to determine that both native and nonnative speakers in the sample show conceptual accessibility effects in speech production, they cannot determine whether the effect is on the assignment of a grammatical function to the conceptually most accessible argument or on its early placement in a syntactic frame. As already discussed, dative stimuli allow these two possibilities to be teased apart. 
Table 7. Recall of double object versus prepositional object datives

\begin{tabular}{|c|c|c|c|}
\hline \multirow[b]{3}{*}{ Stimulus } & \multicolumn{3}{|c|}{$\mathrm{L} 1$} \\
\hline & $\operatorname{Arabic}(N=17)$ & Chinese $(N=15)$ & English $(N=10)$ \\
\hline & $k=136$ & $k=120$ & $k=80$ \\
\hline \multicolumn{4}{|l|}{ Double object } \\
\hline Correct & 47 & 57 & 26 \\
\hline Inversion & 67 & 49 & 47 \\
\hline Other & 22 & 14 & 7 \\
\hline \multirow[t]{2}{*}{ Inversion ratio } & 0.63 & 0.45 & 0.64 \\
\hline & $k=136$ & $k=120$ & $k=80$ \\
\hline \multicolumn{4}{|c|}{ Prepositional object } \\
\hline Correct & 99 & 95 & 68 \\
\hline Inversion & 17 & 12 & 7 \\
\hline Other & 20 & 13 & 5 \\
\hline Inversion ratio & 0.17 & 0.13 & 0.1 \\
\hline
\end{tabular}

Note: L1, first language. Arabic: $z=-3.4, N-$ ties $=16, p=.001$, two-tailed significance; Chinese $z=-3.12, N$ - ties $=13, p=.002$, two-tailed significance; English: $z=-2.81, N-$ ties $=10, p=.005$, two-tailed significance.

The first question we consider in relation to the dative stimuli is whether participants have a production preference for the double object frame (Send the customer the book) or the prepositional object frame (Send the patient to the hospital) overall. Table 7 compares production where the stimulus sentences were dative double objects and where they were prepositional object constructions. Stimulus sentences in both conditions were balanced for the conceptual accessibility of arguments, in that in half of the items a conceptually more accessible argument was adjacent to the verb and in the other half was in clause-final position. Both objects were definite and nonpronominal.

Wilcoxon signed ranks tests suggest that each participant group has an inherent preference for the prepositional object construction in production. Inversions where the stimuli are double objects are greater than where they are prepositional objects.

Against this background, the predictions of the two grammatical function models and the linear precedence model outlined in Table 1 are considered. GF1 assumes that in the dative double object construction (e.g., Send the customer the book), both objects function as DOs, whereas GF2 assumes that the first object retains its status as an $\mathrm{IO}$, with the second one being the DO. The linear precedence model assumes that the conceptual accessibility of lemmas affects precedence in the syntactic frame, with conceptually more accessible lemmas appearing earlier than conceptually less accessible lemmas; grammatical function plays no role. 
Hawkins et al.: Eliminating grammatical function assignment

Table 8. Recall of dative direct object + prepositional phrase stimuli where the conceptual accessibility of object arguments alternates

\begin{tabular}{|c|c|c|c|}
\hline \multirow[b]{3}{*}{ Stimulus } & \multicolumn{3}{|c|}{ L1 } \\
\hline & Arabic $(N=17)$ & Chinese $(N=15)$ & English $(N=10)$ \\
\hline & $k=68$ & $k=60$ & $k=40$ \\
\hline \multicolumn{4}{|c|}{ Send the book to the customer } \\
\hline Correct & 41 & 43 & 30 \\
\hline Inversion & 13 & 8 & 7 \\
\hline Other & 14 & 9 & 3 \\
\hline \multirow[t]{2}{*}{ Inversion ratio } & 0.27 & 0.19 & 0.21 \\
\hline & $k=68$ & $k=60$ & $k=40$ \\
\hline \multicolumn{4}{|c|}{ Send the patient to the hospital } \\
\hline Correct & 58 & 52 & 38 \\
\hline Inversion & 4 & 4 & 0 \\
\hline Other & 6 & 4 & 2 \\
\hline Inversion ratio & 0.07 & 0.07 & 0 \\
\hline
\end{tabular}

Note: L1, first language. Arabic: $z=-2.07, N-$ ties $=12, p=.04$, two-tailed significance; Chinese: $z=-1.56, N-$ ties $=8, p=.12$, two-tailed not significant; English: $z=-2.06$, $N-$ ties $=5, p=.04$, two-tailed significance.

In order to distinguish these models, the first relevant comparison is participant recall of dative prepositional object stimuli of the kind illustrated in (18).

(18) a. The bookshop sent the book to the customer.

b. The doctor sent the patient to the hospital.

The linear precedence model and GF1 predict more inversions in the case of (18a), recalled as The bookshop sent the customer the book, than (18b), recalled as The doctor sent the hospital the patient. This is because in the stimulus sentences the conceptually more accessible customer (IO) is assigned a lower function on the grammatical function hierarchy (than the DO book) or appears later in the syntactic frame. GF2 predicts no difference in inversions between (18a) and (18b) because customer remains an IO whether it appears in the prepositional object construction or the double object construction. Results are shown in Table 8.

Numerically, there is a tendency in all three groups to produce a double object construction when the animate argument in the stimulus does not immediately follow the verb than when it does, consistent with GF1 and the linear precedence model, but not with GF2. However, this difference is only statistically significant in the case of the native speakers and the L1 Arabic group. With relatively small population sizes, and a clear preference in production for all groups for the prepositional dative, caution is needed in interpreting significance. 
Hawkins et al.: Eliminating grammatical function assignment

Table 9. Recall of dative double object stimuli where the conceptual accessibility of object arguments alternates

\begin{tabular}{|c|c|c|c|}
\hline \multirow[b]{3}{*}{ Stimulus } & \multicolumn{3}{|c|}{ L1 } \\
\hline & Arabic $(N=17)$ & Chinese $(N=15)$ & English $(N=10)$ \\
\hline & $k=68$ & $k=60$ & $k=40$ \\
\hline \multicolumn{4}{|c|}{ Send the hospital the patient } \\
\hline Correct & 21 & 26 & 6 \\
\hline Inversion & 38 & 25 & 31 \\
\hline Other & 9 & 9 & 3 \\
\hline \multirow[t]{2}{*}{ Inversion ratio } & 0.66 & 0.46 & 0.80 \\
\hline & $k=68$ & $k=60$ & $k=40$ \\
\hline \multicolumn{4}{|c|}{ Send the customer the book } \\
\hline Correct & 26 & 31 & 20 \\
\hline Inversion & 29 & 24 & 16 \\
\hline Other & 13 & 5 & 4 \\
\hline Inversion ratio & 0.59 & 0.44 & 0.44 \\
\hline
\end{tabular}

Note: L1, first language. Arabic: $z=-0.54, N-$ ties $=14, p=.59$, two-tailed not significant; Chinese: $z=-0.09, N-$ ties $=11, p=.93$, two-tailed not significant; English $z=-2.71, N-$ ties $=8, p=.007$, two-tailed significance.

In particular, variation in the proficiency of the L2 speakers may be a factor. Less proficient speakers of English may not yet have had sufficient exposure to English to fully acquire the two constructions involved in the dative alternation. And it is this, rather than difficulty with the integration of grammatical knowledge with the production planning mechanisms, that is producing weak effects. $^{7}$

The second relevant comparison, to distinguish GF1 from the linear precedence model, is the recall of sentence types like (19).

(19) a. The doctor sent the hospital the patient.

b. The bookshop sent the customer the book.

The linear precedence model predicts more inversions in the case of (19a) than (19b) because the conceptually more accessible argument (patient) comes later in the syntactic frame than the less accessible argument (hospital). In GF1, for which both arguments are DOs in the dative double object construction, there is no reason to expect a difference in frequency of inversions between (19a) and (19b) since in both cases the conceptually more accessible argument is a DO. Results are presented in Table 9.

These results are consistent, for the native speakers, with the linear precedence model, but not with GF1. The L2 speakers are not showing a significant difference 
Hawkins et al.: Eliminating grammatical function assignment

Table 10. Recall by proficiency of dative double object stimuli where the conceptual accessibility of object arguments alternates

\begin{tabular}{|c|c|c|}
\hline \multirow[b]{3}{*}{ Stimulus } & \multicolumn{2}{|c|}{ Proficiency } \\
\hline & Intermediate $(N=22)$ & Advanced $(N=18)$ \\
\hline & $k=88$ & $k=72$ \\
\hline \multicolumn{3}{|c|}{ Send the hospital the patient } \\
\hline Correct & 40 & 12 \\
\hline Inversion & 35 & 55 \\
\hline Other & 13 & 5 \\
\hline \multirow[t]{2}{*}{ Inversion ratio } & 0.46 & 0.82 \\
\hline & $k=88$ & $k=72$ \\
\hline \multicolumn{3}{|c|}{ Send the customer the book } \\
\hline Correct & 47 & 30 \\
\hline Inversion & 33 & 31 \\
\hline Other & 7 & 11 \\
\hline Inversion ratio & 0.43 & 0.53 \\
\hline
\end{tabular}

Note: Intermediate: $z=-0.07, N$ - ties $=18, p=.95$, two-tailed not significant; Advanced: $z=-3.22, N$ - ties $=14, p=.001$, two-tailed significance.

in proportions of inversions in the two contexts. Suspecting that proficiency is playing a role in determining production patterns, results were recoded by proficiency: intermediate versus advanced (Table 10).

The results show that the advanced proficiency group, which includes 8 of the L2 speakers, shows a stronger tendency to produce a prepositional object dative in response to a double object dative stimulus if the result is to place a conceptually more accessible DP argument adjacent to the verb. This is consistent with the linear precedence model but not with GF1 both for native speakers and for advanced proficiency L2 speakers of English.

It thus appears that the effect of the conceptual accessibility of lemmas combined with incrementality of production processing activates syntactic frames for the English dative construction, which allows the selected lemma to appear earlier in the frame. There is no evidence that the grammatical functions of the arguments involved play any role.

\section{DISCUSSION}

It was argued earlier in the article that, on theoretical grounds, grammatical function assignment is redundant in a hierarchical model of speech production where the assignment of thematic roles by a verb (or more precisely a predicate) to the lemmas that constitute its arguments is necessary, and where incrementality of production processing is assumed. The elimination of grammatical functions 
from the model means that the known effects of conceptual accessibility only concern linear precedence in syntactic frames. In the previous section, the results of a study of the effects of conceptual accessibility on the selection of the two syntactic frames associated with dative verbs found evidence that these effects were on linear precedence but not grammatical function assignment in native speakers and in L2 speakers of English of high proficiency. These findings go together with those of Branigan and Feleki (1999) in a study of native speakers of Greek and with some of the results of the study by Tanaka et al. (2005) of native speakers of Japanese. However, to maintain this view, it is necessary to deal with the other findings of Tanaka et al. that conceptual accessibility also affects grammatical function assignment in Japanese and, furthermore, to address the repeated finding that in conjoined DPs involving a conceptually more accessible lemma and a conceptually less accessible one, there is no effect of conceptual accessibility on ordering (e.g., winter and time/time and winter, the manager and the key/the key and the manager; Bock \& Warren, 1985; McDonald et al., 1993).

Tanaka et al. (2005) conducted two recall experiments with native speakers of Japanese. In the first experiment, the stimulus sentences consisted only of active sentences with one animate and one inanimate argument but presented in one of two possible word orders: canonical SOV or scrambled OSV order, as illustrated in (20).

$\begin{array}{ccc}\text { (20) a. Ryokousha-ga takushii-o tukemaeta } & \text { (SOV) } \\ \text { traveller-Nom taxi-Acc pick-up-past } & \\ \text { "A traveler picked up a taxi." } & \\ \text { b. Takushii-ga ryokousha-o tukemaeta } & \text { (SOV) } \\ \text { taxi-Nom traveller-Acc pick-up-past } & \\ \text { "A taxi picked up a traveler." } & \\ \text { c. Takushii-o ryokousha-ga tukemaeta } & \text { (OSV) } \\ \text { taxi-Acc traveller-Nom pick-up-past } & \\ & \text { "As for the taxi, a traveler picked it up." } & \\ \text { d. Ryokousha-o takushii-ga tukemaeta } & \text { (OSV) } \\ & \text { traveller-Acc taxi-Nom pick-up-past } & \\ & \text { "As for the traveler, a taxi picked him up." } & \end{array}$

Participants in this experiment were more likely to recall OSV sentence stimuli of the kind illustrated in (20c) as (20a), putting the animate subject in first position in the clause (56\% inversions) than they were to recall (20d) as (20b), putting the inanimate subject back in first position (37\% inversions). This is consistent with the claim that a conceptually more accessible lemma claims first position in a syntactic frame, regardless of grammatical function.

However, the results from Tanaka et al.'s (2005) second experiment are the problematic ones for the claim that conceptual accessibility activates syntactic frames that put the conceptually more accessible lemma earlier. In this experiment, participants were presented not only with active stimuli like those in (20) but also with passive stimuli in canonical and scrambled word order, illustrated in (21). 
Hawkins et al.: Eliminating grammatical function assignment

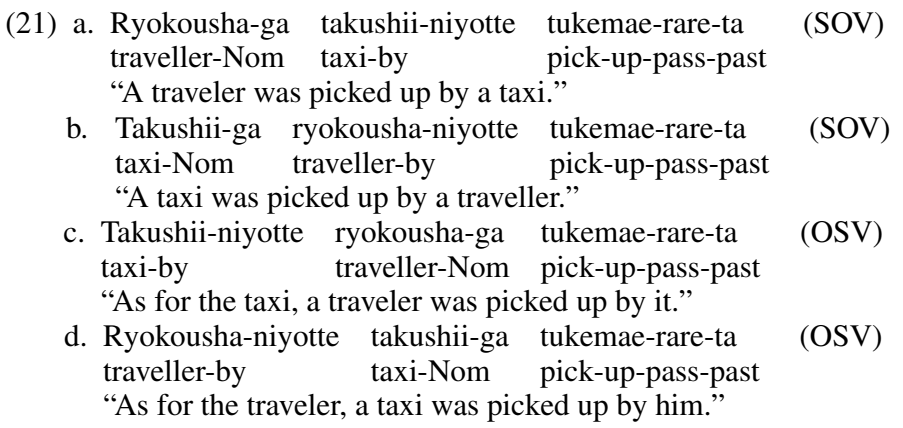

In this case, Tanaka et al. found that participants tended to recall the scrambled active (20d) as the scrambled passive (21c) where traveler has been shifted from clause initial position to subject position ( $41 \%$ inversions). Similarly, they recalled scrambled passive (21d) as scrambled active (20c), again shifting the clause-initial animate participant to a noninitial subject position (35\% inversions).

These results led Tanaka et al. (2005) to argue that conceptual accessibility gives rise both to early positioning in the clause and assignment to a higher grammatical function on the grammatical function hierarchy. Since early positioning is a feature of the positional level of speech planning, whereas grammatical function assignment is a feature of the functional level, if both effects can occur in speech production planning, this must mean that there is only one level of syntactic planning.

However, there are some aspects of the results that suggest that word ordering properties in Japanese are rather different from those in English and cast some doubt on this interpretation. First, as shown both in previous studies and in the present study, native speakers of English have an inherent preference for actives over passives in speech production, particularly where one of the arguments is animate and the other is not (e.g., preferring The farmer bought the fridge over The fridge was bought by the farmer). In the present study, out of 50 stimulus sentences of the type The fridge was bought by the farmer, there were 37 inversions (74\%). By contrast, in Tanaka et al.'s (2005) second experiment, inversions where the stimulus was the parallel case (20b) were only $6 \%$. The range of inversions in response to all SOV stimuli in Experiment 2 is only 2\%-14\%, whereas the range of inversions in response to all OSV stimuli goes from $12 \%$ to $41 \%$. Crucially, the highest numbers of inversions occur where an animate argument is in the scrambled first position ( $41 \%$ and $35 \%)$. In cases where an inanimate is in the scrambled first position, inversions are only $16 \%$ and $12 \%$. These results suggest to us that in Japanese the main effect of the conceptual accessibility of a lemma is to promote the selection of a syntactic frame where it can appear as an argument in canonical SOV word order, and the appearance of a conceptually more accessible lemma in the first position of that frame is of less importance. This may be because scrambled OSV word order in Japanese satisfies information structure requirements and is not itself determined at the positional level of speech planning. This is currently only speculation. At any rate, we conclude that the results from the Tanaka et al. study 
do not offer compelling reasons for assuming that the conceptual accessibility of lemmas affects both grammatical function assignment and earlier positioning in the syntactic frame.

The other counterevidence to the claim that conceptual accessibility affects earlier positioning rather than grammatical function assignment that needs to be considered is the finding in the studies of Bock and Warren (1985) and McDonald et al. (1993) that conceptual accessibility has no effect on word order in conjoined DPs in the recall of sentences like The lost hiker fought time and winter/winter and time (Bock \& Warren, 1985) or The crew and the camera/The camera and the crew suffered minor injuries (McDonald et al., 1993). Branigan et al. (2008, p. 186) suggest that coordinations are "special structures" that, because they are multiply headed, may be "processed in unusual ways." They also point out that for syntactic purposes (e.g., for subject-verb agreement), conjoined NPs are treated as a single DP with combined features from the constituent phrases. This is why conjoined DPs typically give rise to plural agreement (Winter and time are/*is a danger to the lost hiker). They go on to argue that "it seems plausible that conjunctions are not processed incrementally like other phrases .... When processing a conjunctive phrase, the processor temporarily suspends fully incremental processing ... until the lemmas associated with both conjuncts have been successfully retrieved." If this is the case, the lack of conceptual accessibility effects on the order of DPs in conjoined phrases is no longer counterevidence to the linear precedence model. Both noun lemmas are active when the syntactic frame for conjoined phrases is selected at the positional level.

The elimination of grammatical function assignment does not mean the reduction of syntactic planning to a single level. A level of processing is still required at which lemmas are selected, and noun lemmas are co-indexed with the appropriate thematic roles of the verb/predicate (whether this level is called "functional" or something else). This level of planning must precede the positional level in order to allow for the incrementality of processing.

Finally, evidence from the L2 speakers in the study suggests that they integrate information about the conceptual accessibility of referents with the selection of syntactic constructions during speech production in a similar way to native speakers, at least when their proficiency in English is advanced. As argued above, this need not have been the case. They might in principle have shown no effect of conceptual accessibility on the selection of syntactic frames, or even an anticonceptual accessibility effect, where the less conceptually accessible argument appears in an earlier position. The interface hypothesis about L2 acquisition suggests that the properties of the interface "between syntax and other domains ... may never be completely acquired by L2 learners" (Sorace, 2005, Example 26). Whether or not this holds for comprehension, it does not appear to hold for the interface between syntactic representation and the accessibility of concepts in speech production.

\section{CONCLUSION}

It has been argued that grammatical function assignment, which has been a key characteristic of hierarchical models of speech production, is unnecessary on theoretical and empirical grounds. Theoretically, the assignment by a verb/ 
Hawkins et al.: Eliminating grammatical function assignment

predicate of its thematic roles to accompanying noun lemmas together with incrementality of processing (both of which are required in existing models) are sufficient to explain the effects of the conceptual accessibility of referents on the selection of particular syntactic frames. Empirically, it was shown that grammatical function assignment makes the wrong predictions about the effects of conceptual accessibility on the production of dative double object and preposition object constructions in the speech of native and advanced proficiency nonnative speakers of English. A secondary goal of the study was to test whether L2 speakers of English successfully integrate syntactic knowledge with the conceptual accessibility of referents during speech production planning. A current hypothesis in L2 acquisition research suggests that L2 learners may have persistent difficulty at such interfaces. The findings indicate that the advanced proficiency speakers in the present study do not.

\section{APPENDIX A}

The following is an illustrative block of stimulus sentences followed by a proficiency test distractor.

1. John promised his wife the holiday in Spain.

2. At the hotel, the guests were arriving.

3. In the harbor, the sailor was carried by the boat.

4. At the café, the policeman rested happily.

5. The postman sold the bike to the painter.

Choose the word that best fits each space

\section{THE STARS}

There are millions of stars in the sky. If you look (6) ............ the sky on a clear night, it is possible to see about 3,000 stars. They look small, but they are really (7) ............ big hot balls of burning gas. Some of them are huge, but others are much smaller, like our planet Earth. The biggest stars are very bright, but they only live for a short time. Every day new stars (8) ........... born and old stars die. All the stars are very far away. The light from the nearest star takes more (9) ............. four years to reach Earth. Hundreds of years ago, people (10) ............... stars, like the North Star, to know which direction to travel in. Today you can still see that star.

$\begin{array}{lll}\text { 6. A at } & \text { B up } & \text { C on } \\ \text { 7. A very } & \text { B too } & \text { C much } \\ \text { 8. A is } & \text { B be } & \text { C are } \\ \text { 9. A that } & \text { B of } & \text { C than } \\ \text { 10. A use } & \text { B used } & \text { C using }\end{array}$

\section{APPENDIX B: TEST ITEMS}

The following contains a list of the types of sentences. 
Hawkins et al.: Eliminating grammatical function assignment

Type 1 sentences: Participants of the same level of conceptual accessibility, actives

1. At the university, the student greeted the professor.

2. In the school, the child surprised the teacher.

3. At the party, the patient criticized the doctor.

4. At the cinema, the baker admired the actress.

5. At the ballet, the sailor watched the dancer.

Type 2 sentences: Participants of the same level of conceptual accessibility, passives

6. At the university, the professor was greeted by the student.

7. In the school, the teacher was surprised by the teacher.

8. At the party, the doctor was criticized by the patient.

9. At the cinema, the actress was admired by the baker.

10. At the ballet, the dancer was watched by the sailor.

Type 3 sentences: Participants of different levels of conceptual accessibility, nonreversible verbs, actives

11. At the market, the farmer bought the fridge.

12. In the restaurant, the waiter opened the bottle.

13. In the village, the policeman rode the bicycle.

14. At the gallery, the artist sold the painting.

15. In the kitchen, the cook baked the cake.

Type 4 sentences: Participants of different levels of conceptual accessibility, nonreversible verbs, passives

16. At the market, the fridge was bought by the farmer.

17. In the restaurant, the bottle was opened by the waiter.

18. In the village, the bicycle was ridden by the policeman.

19. At the gallery, the painting was sold by the artist.

20. In the kitchen, the cake was baked by the cook.

Type 5 sentences: Participants of different levels of conceptual accessibility, reversible verbs, actives

21. In the harbor, the boat carried the sailor.

22. On the mountain, the ice crushed the climber.

23. At the station, the bell hit the fireman.

24. In the dark room, the wire cut the electrician.

25. After the journey, the soup warmed the walker. 
Hawkins et al.: Eliminating grammatical function assignment

Type 6 sentences: Participants of different levels of conceptual accessibility, reversible verbs, passives

26. In the harbor, the sailor was carried by the boat.

27. On the mountain, the climber was crushed by the ice.

28. At the station, the fireman was hit by the bell.

29. In the dark room, the electrician was cut by the wire.

30. After the journey, the walker was warmed by the soup.

Type 7 sentences: Dative DO with accessible participant last

31. The doctor sent the local hospital the patient.

32. The football club sold the other team its best player.

33. The boss offered the new company his best manager.

34. The writer lent the organization her personal assistant.

\section{Type 8 sentences: Dative PP with accessible participant first}

35. The doctor sent the patient to the local hospital.

36. The football club sold its best player to the other team.

37. The boss offered his best manager to the new company.

38. The writer lent her personal assistant to the organization.

\section{Type 9 sentences: Dative DO with accessible participant first}

39. The bookshop sent the customer the book.

40. The postman sold the painter the bike.

41. John promised his wife the holiday in Spain.

42. The mechanic lent his friend the car.

\section{Type 10 sentences: Dative PP with accessible participant last}

43. The bookshop sent the book to the customer.

44. The postman sold the bike to the painter.

45. John promised the holiday in Spain to his wife.

46. The mechanic lent the car to his friend.

\section{Type 11 sentences: Intransitive fillers, past progressive}

47. At the library, the professor was reading.

48. At the hospital, the nurse was working.

49. In the garden, the man was digging.

50. At the hotel, the guests were arriving.

51. At the restaurant, the actors were eating.

52. Outside the cinema, the sailors were talking.

53. In the woods, the birds were singing.

54. In the armchair, the writer was sleeping.

55. In the playground, the child was laughing. 
Hawkins et al.: Eliminating grammatical function assignment

56. At the concert, the audience was listening.

57. In the square, the soldiers were marching.

58. In the stadium, the athletes were running.

59. In the study, the novelist was writing.

60 . In the sitting room, the fire was burning.

61. In the sea, the children were swimming.

62. At the café, the policeman was resting.

63. In the park, people were walking.

\section{Type 12 sentences: Intransitive fillers, simple past}

64. At the library, the professor read quietly.

65. At the hospital, the nurse worked carefully.

66. In the garden, the man dug slowly.

67. At the hotel, the guests arrived noisily.

68. At the restaurant, the actors ate well.

69. Outside the cinema, the sailors talked loudly.

70. In the woods, the birds sang beautifully.

71. In the armchair, the writer slept peacefully.

72. In the playground, the child laughed cheerfully.

73. At the concert, the audience listened attentively.

74. In the square, the soldiers marched vigorously.

75. In the stadium, the athletes ran quickly.

76. In the study, the novelist wrote silently.

77. In the sitting room, the fire burned fiercely.

78. In the sea, the children swam joyfully.

79. At the café, the policeman rested happily.

80. In the park, people walked slowly.

\section{ACKNOWLEDGEMENTS}

We thank the editors and three anonymous reviewers for detailed comments on earlier drafts of this manuscript. Any remaining weaknesses are our own.

\section{NOTES}

1. We put to one side the question of what form the entry takes, whether it is a network of connected nodes each representing a different feature of conceptual and grammatical information, as proposed by Levelt, Roelofs, and Meyer (1999), or some other system.

2. A reviewer asks what this account has to say about the kinds of naturally occurring speech error that originally motivated a speech production model where grammatical functions are assigned, and cites examples of exchange errors like the following, where subject-verb agreement matches the moved NP rather than the real subject: most cities are true of that (intended: that is true of most cities). The question is, how can subjectverb agreement be explained here unless the error involves most cities wrongly having been assigned the subject function? Subject-verb agreement is a misnomer within the 
Hawkins et al.: Eliminating grammatical function assignment

framework adopted here. Agreement is a relation between an inflectional category that is a constituent in positional level syntactic frames and another constituent that is inserted into the inflectional category's specifier position. The inflectional category has an unvalued number feature (represented by $\alpha$ in the following frame) whose value is assigned by whatever appears in the position to its left: [ [NP _ _ Infl $\alpha$ number __ be [Adj [of ${ }_{\mathrm{NP}}$ _ ] ] ]. The appearance of most cities in the first NP position rather than that (which is most likely conceptually more accessible by virtue of being a discourse topic referring to some previously made statement) is an error made by the positional-level processor. However, the consequence of the error is that most cities values the number feature of Infl. That agreement is determined between an inflectional category and a constituent appearing to its left, rather than with a constituent assigned the function "subject," is suggested by attraction agreement errors of the kind: The cost of running the hotels are very high. Here hotels is not the subject of are very high. Studies that have elicited errors of this type have found they represent about $6 \%$ of agreement cases (Bock \& Miller, 1991). Such misagreements are consistent with a model where the value of the inflectional category is determined by a constituent appearing to its left.

3. The claim that "no access to thematic role information at the positional level is required" is not inconsistent with recent studies that have found that thematic roles in stimulus sentences can prime thematic roles in subsequently produced sentences independently of syntactic structure. For example, in a study of Dutch speakers, Vernice et al. (2011) found that the patient role of cowboy focused in (the Dutch equivalent of) the cleft sentence It was the cowboy that he was hitting primed the production of unrelated passive sentences where the patient appears in first position in the sentence, such as The man is being suffocated by the smoke (see also Chang et al., 2003). On the assumption that "priming effects can occur at every processing level during language production" (Vernice, 2011, p. 13), it appears that these are effects at the message (conceptual) level, where it is assumed in this study that the thematic function of referential concepts in the event is necessarily specified. We thank a reviewer for drawing our attention to this work.

4. Team, company, organization, as collective nouns referring to groups made up of animate members, may be borderline animates themselves. However, we have assumed that they are less predicable than clearly animate nouns like player and manager. We were forced into using collectives by the difficulty of constructing double object datives where the first object is inanimate, for example, The manager lent the other team his best player.

5. In half of the prompts, the vertical ordering corresponded to the left to right ordering of arguments in the stimulus sentences. In the other half, the order was reversed. The matching and mismatching orders were equally distributed across the stimulus types.

6. Although there has been considerable work on syntactic and semantic priming effects in bilinguals and L2 speakers (see McDonough \& Trofimovich, 2009, for a review), to our knowledge there are few studies that focus on priming-independent properties of production planning at the functional and positional levels in L2 speakers, particularly where conceptual accessibility is a factor.

7. Recoding of the participants into two proficiency groups (intermediate and advanced) showed a stronger effect of conceptual accessibility on inversion where the animate argument appeared in the PP. 
Hawkins et al.: Eliminating grammatical function assignment

\section{REFERENCES}

Bock, J. K. (1986). Syntactic persistence in language production. Cognitive Psychology, 18, 355-387.

Bock, J. K., \& Levelt, W. J. M. (1994). Language production: Grammatical encoding. In M. A. Gernsbacher (Ed.), Handbook of psycholinguistics (pp. 945-984). San Diego, CA: Academic Press.

Bock, J. K., \& Loebell, H. (1990). Framing sentences. Cognition, 35, 1-39.

Bock, J. K., \& Miller, C. A. (1991). Broken agreement. Cognitive Psychology, 23, 45-93.

Bock, J. K., \& Warren, R. K. (1985). Conceptual accessibility and syntactic structure in sentence formulation. Cognition, 21, 47-67.

Branigan, H. P., \& Feleki, E. (1999). Conceptual accessibility and serial order in Greek language production. In M. Hahn \& S. C. Stones (Eds.), Proceedings of the 21st Annual Conference of the Cognitive Science Society (pp. 96-101). Mahwah, NJ: Erlbaum.

Branigan, H. P., Pickering, M. J., \& Tanaka, M. (2008). Contributions of animacy to grammatical function assignment and word order during production. Lingua, 118, 172-189.

Bresnan, J. (2001). Lexical-functional syntax. Malden, MA: Wiley.

Chang, F., Bock, K., \& Goldberg, A. E. (2003). Can thematic roles leave traces of their places? Cognition, 90, 29-49.

Ferreira, F. (1994). Choice of passive voice is affected by verb type and animacy. Journal of Memory and Language, 33, 715-736.

Ferreira, F., \& Engelhardt, P. E. (2006). Syntax and production. In M. J. Traxler \& M. A. Gernsbacher (Eds.), Handbook of psycholinguistics (2nd ed., pp. 61-91). London: Academic Press.

Garrett, M. F. (1975). The analysis of sentence production. In G. Bower (Ed.), Psychology of learning and motivation (Vol. 9, pp. 177-220). New York: Academic Press.

Goldman-Eisler, F., \& Cohen, M. (1970). Is N, P, and PN difficulty a valid criterion of transformational operations? Journal of Verbal Learning and Verbal Behaviour, 9, 161-166.

Keenan, E., \& Comrie, B. (1977). Noun phrase accessibility and universal grammar. Linguistic Inquiry, $8,63-99$.

Kempen, G., \& Hoenkamp, E. (1987). An incremental procedural grammar for sentence formulation. Cognitive Science, 11, 201-258.

Levelt, W. J. M. (1989). Speaking: From intention to articulation. Cambridge, MA: MIT Press.

Levelt, W. J. M., Roelofs, A., \& Meyer, A. (1999). A theory of lexical access in speech production. Behavioral and Brain Sciences, 22, 1-75.

McDonald, J. L., Bock, K., \& Kelly, M. H. (1993). Word and world order: Semantic, phonological, and metrical determinants of serial position. Cognitive Psychology, 25, 188-230.

McDonough, K., \& Trofimovich, P. (2009). Using priming methods in second-language research. London: Routledge.

Oxford Quick Placement Test. (2002). Oxford: Oxford University Press.

Pickering, M. J., \& Branigan, H. P. (1998). The representation of verbs: Evidence from syntactic persistence in written language production. Journal of Memory and Language, 39, 633-651.

Pickering, M. J., Branigan, H. P., \& McLean, J. F. (2002). Constituent structure is formulated in one stage. Journal of Memory and Language, 46, 586-605.

Potter, M. C., \& Lombardi, L. (1990). Regeneration in the short-term recall of sentences. Journal of Memory and Language, 29, 633-654.

Prat-Sala, M., \& Branigan, H. P. (1999). Discourse constraints on syntactic processing in language production: A cross-linguistic study in English and Spanish. Journal of Memory and Language, $42,168-182$.

Ryding, K. (2005). A reference grammar of Modern Standard Arabic. Cambridge: Cambridge University Press.

Sorace, A. (2005). Selective optionality in language development. In L. Cornips \& K. Corrigan (Eds.), Syntax and variation: Reconciling the biological and the social (pp. 55-80). Amsterdam: John Benjamins.

Sorace, A., \& Filiaci, F. (2006). Anaphora resolution in near-native speakers of Italian. Second Language Research, 22, 339-368.

Tanaka, M., Branigan, H. P., \& Pickering, M. J. (2005). The role of animacy in Japanese sentence production. Paper presented at the CUNY Sentence Processing Conference, Tucson.

Vernice, M., Pickering, M. J., \& Hartsuiker, R. J. (2011). Thematic emphasis in language production. Language and Cognitive Processes, 27, 631-664.

White, L. (2011). Second-language acquisition at the interfaces. Lingua, 577-590. 